\title{
Proteinuria asociada al dengue
}

\section{Proteinuria associated with dengue}

Autores: Daiana Correa, ${ }^{1}$ Raúl Real, ${ }^{2}$ Gustavo Rojas, ${ }^{1}$ María de los Ángeles Barrios, ${ }^{1}$ Fabián Aldama, ${ }^{1}$ Valeria Fridman, ${ }^{1}$ Alejandro Valenzuela ${ }^{1}$

\section{Resumen}

Objetivos: describir el grado de proteinuria y albuminemia en pacientes con dengue, correlacionar la proteinuria con la fuga capilar medida por el nivel de hemoconcentración de la hemoglobina y hematocrito.

Metodología: diseño observacional, descriptivo, prospectivo, de corte transversal. Población de estudio: varones y mujeres, mayores de edad, portadores de dengue, internados en el Dpto. de Medicina Interna entre diciembre 2012 y mayo 2013. Criterios de inclusión: dengue grave con signos de alarma, confirmado por antígeno NS1 y/o IgM positivo, en periodo crítico o postfebril. Criterios de exclusión: portadores de afecciones renales conocidas. Muestreo no probabilístico de casos consecutivos. Variables: datos demográficos, hemograma, proteinuria de $24 \mathrm{hs}$, albuminemia.

Resultados: ingresaron al estudio 26 varones con edad media $42 \pm 21$ años y 28 mujeres con edad media $41 \pm 21$

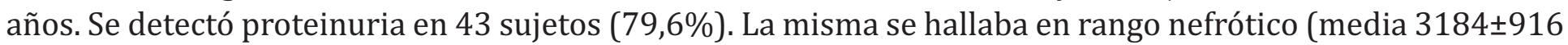
$\mathrm{mg} / 24 \mathrm{hs}$ ) en 8 casos $(14,8 \%$ ) y dentro de valores elevados (media $669 \pm 494 \mathrm{mg} / 24 \mathrm{hs}$ ) en 35 casos $(64,8 \%)$. La albuminemia en los sujetos con rango nefrótico fue $3 \pm 0,7 \mathrm{mg} / \mathrm{dL}$, en los que tenían valores elevados de proteinuria fue $2,9 \pm 0,4 \mathrm{mg} / \mathrm{dL}$ y en los sujetos sin proteinuria fue $2,6 \pm 0,4 \mathrm{mg} / \mathrm{dL}$ (p 0,09 prueba ANOVA). La correlación entre proteinuria y grado de hemoconcentración de hemoglobina fue $\quad-0,01$ y con el grado de hemoconcentración del hematocrito fue -0,04.

Conclusiones: el dengue produjo proteinuria en 79,6\% de los pacientes, llegando a rango nefrótico en 14,8\%. La proteinuria no se asoció con el grado de hemoconcentración de la hemoglobina ni del hematocrito, parámetros utilizados como indicadores de gravedad de la fuga capilar. Se recomienda agregar el dosaje de proteínas en orina de 24 hs al protocolo de tratamiento del dengue y el seguimiento prospectivo de los afectados con rango nefrótico.

Palabras claves: dengue, proteinuria, síndrome nefrótico

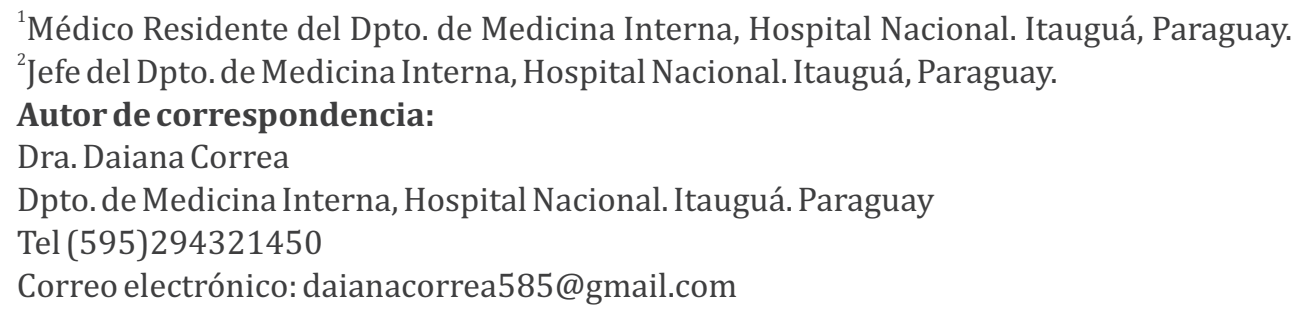




\section{Abstract}

Objectives: To describe the degree of proteinuria and serum albumin in patients with dengue and correlate the proteinuria with the capillary leakage measured by the level of hemoglobin and hematocrit hemoconcentration.

Methods: This was a cross-sectional, prospective, descriptive and observational study. Study population: adult men and women, dengue carriers and admitted in the Department of Internal Medicine between December 2012 and May 2013. Inclusion criteria: severe dengue with warning signs, confirmed by positive NS1 antigen and/or IgM in post-febrile or critical period. Exclusion criteria: known kidney disease carriers. Non-probabilistic sampling of consecutive cases. Variables: demographic data, hemogram, 24-hour proteinuria, serum albumin.

Results: Twenty six men with a mean age of $42 \pm 21$ years and 28 women with a mean age of $41 \pm 21$ years were included in the study. Proteinuria was detected in 43 subjects $(79.6 \%)$. The proteinuria was in nephrotic range (mean 3,184 $\pm 916 \mathrm{mg} / 24 \mathrm{~h}$ ) in 8 cases (14.8\%) and in high values (mean $669 \pm 494 \mathrm{mg} / 24 \mathrm{~h}$ ) in 35 cases (64.8\%). The serum albumin was $3 \pm 0.7 \mathrm{mg} / \mathrm{dL}$ in patients with nephrotic range, $2.9 \pm 0.4 \mathrm{mg} / \mathrm{dL}$ in those with high levels of proteinuria and $2.6 \pm 0.4 \mathrm{mg} / \mathrm{dL}(\mathrm{p}=0.09$ ANOVA test) in subjects without proteinuria. The correlation between the proteinuria and degree of hemoglobin hemoconcentration was -0.01 while the correlation between the proteinuria and degree of hematocrit hemoconcentration was -0.04 .

Conclusions: Proteinuria associated with dengue was observed in $79.6 \%$ of the patients reaching the nephrotic range in $14.8 \%$. The proteinuria was not associated with the degree of hemoglobin or hematocrit hemoconcentration, the parameters commonly used as indicators of the severity of the capillary leakage. It is recommended to add protein dosage in 24-hour urine in the treatment protocol of dengue as well as the prospective follow-up of those patients with nephrotic range.

Keywords: dengue, proteinuria, nephrotic syndrome

\section{Introducción}

El dengue es una infección viral producida por un Arbovirus, afectando a regiones tropicales y subtropicales en todos los continentes. Los cuatro serotipos de dengue son infectantes para los seres humanos y capaces de producir formas graves, incluso letales. Tiene diferentes presentaciones clínicas y la mayoría se manifiesta en forma subclínica o asintomática (53-87\%). En los sujetos sintomáticos, el cuadro clínico puede oscilar entre una fiebre leve hasta formas graves de shock y hemorragias mortales. A pesar de ser más grave en sujetos con comorbilidades, su evolución clínica es impredecible, lo que la hace peligrosa en cualquier situación. ${ }^{1}$

Es una enfermedad muy dinámica, a pesar de ser de corta duración: no más de una semana en casi el 90\% de los casos. Su expresión puede modificarse con el paso de los días y puede también agravarse de manera súbita. Tras un periodo de incubación asintomático de 4-10 días, la enfermedad comienza bruscamente y presenta tres fases: 1 - fase febril, de inicio brusco con sintomatología similar a la de otras virosis; 2-fase crítica, que coincide con la defervescencia de la fiebre, donde puede ocurrir escape de plasma con aumento progresivo del hematocrito y disminución de plaquetas con las consiguientes complicaciones de las mismas; 3- fase de recuperación, con desaparición de las molestias, estabilización del paciente y en ocasiones prurito. ${ }^{2}$ 
El genoma viral RNA es una poli proteína consistente en tres proteínas estructurales (proteína C core, proteína M membrana y proteína capsular E) y siete proteínas no estructurales (NS1, NS2A, NS2B, NS3, NS4A, NS4B, NS5). La proteína NS1 es una glicoproteína de 50 kDA (353 o 354 aminoácidos) que no forman parte del virión pero que se liberan de las células infectadas por el dengue. ${ }^{3,4}$

Su detección por ELISA o test rápidos tiene una sensibilidad entre 87 y $99 \%$ y especificidad entre 82 y $84 \%$ facilitando el diagnóstico precoz del dengue. ${ }^{5,6}$ Los falsos negativos pueden deberse al aclaramiento de estas partículas por inmunoglobulinas presentes en los casos de infecciones secundarias. Los falsos positivos pueden deberse a reacciones cruzadas con anticuerpos dirigidos contra otros flavivirus (fiebre amarilla, encefalitis japonesa) o inmunocomplejos. ${ }^{7}$

Otros estudios encontraron que los resultados de NS1 variaron de acuerdo al serotipo del virus del dengue, del estado inmunológico del paciente y de la severidad de la infección. ${ }^{8}$

Pasados los 5 días, la seroconversión de anticuerpos IgM e IgG por hemaglutinación o ELISA permite confirmar el diagnóstico. El aumento de IgM denota una infección reciente y la IgG una infección reciente o antigua. La vacunación reciente contra la fiebre amarilla puede dar resultados positivos. ${ }^{1}$

El principal órgano blanco del dengue es el endotelio vascular y los elementos formes de la sangre. El daño funcional, no morfológico, de estas células por la propia replicación viral intracelular y como consecuencia de la gran liberación de citoquinas, produce un aumento de la permeabilidad capilar con fuga plasmática al intersticio de todos los órganos. ${ }^{9}$ Como consecuencia de estos fenómenos es frecuente observar plaquetopenia, leucopenia, hemoconcentración. Pero existen reportes de daños más o menos severos de diversos órganos. La etiopatogenia de las formas graves se debe al aumento de la permeabilidad vascular y a los trastornos hemorrágicos causados por la infección. ${ }^{3}$

Entre los mecanismos íntimos del daño celular se cita a los inmunocomplejos, efecto de los linfocitos T, reacción cruzada entre los anticuerpos circulantes y el endotelio vascular, aumento de los anticuerpos y complemento, mediadores solubles como las citoquinas, cepas extremadamente virulentas, pero el más reconocido es la gran liberación de anticuerpos y citoquinas cuando ocurre una segunda infección generando lo que se conoce como "tsunami de citoquinas". Característicamente, las manifestaciones clínicas de las complicaciones inician a partir del tercer día de enfermedad, cuando la fiebre cede y la viremia se halla en descenso, pero coincide con el aumento de las defensas inmunes del cuerpo. ${ }^{9}$

Por otro lado, es bien sabido que pueden generarse fenómenos autoinmunes con diversos virus: HIV, hepatitis C, citomegalovirus, virus herpes simple, virus Epstein-Barr y virus del dengue. Los anticuerpos dirigidos contra el antígeno NS1 muestran reactividad cruzada con las plaquetas humanas y las células endoteliales, lo que lleva a su inflamación y destrucción. ${ }^{10}$

Afectación renal: algunos autores han descrito casos de proteinuria aún en ausencia de alteración de la función renal en $12 \%$ de niños con dengue y no asociado al descenso de plaquetas ni la hemoconcentración del hematocrito. ${ }^{3}$ Otros autores hallaron valores tan altos de proteinuria como $22 \%{ }^{11}$ Sin embargo, otros investigadores han encontrado clara asociación entre proteinuria y formas graves de dengue. ${ }^{12}$ No sólo se filtra albúmina, sino otras moléculas como transferrina, antitrombina y glucosaminoglicanos. ${ }^{12}$ Esta proteinuria se explicaría por el aumento de la permeabilidad vascular glomerular y se asocia al descenso de plaquetas y a las formas graves de dengue. ${ }^{3,11}$ Algunos autores han observado casos con rango nefrótico que se asocian a nefropatía IgA confirmada por estudios histopatológicos, debido a una glomerulonefritis por depósito de inmunocomplejos circulantes. ${ }^{11}$ Otra investigación demostró la alteración en el glicocálix de las células endoteliales glomerulares en el aumento de la permeabilidad. ${ }^{12}$ 
Afortunadamente, no se vio que la proteinuria se relacione con deterioro severo de la función renal ni tampoco con la persistencia en un tiempo superior a 28 días. ${ }^{11}$ La resolución de proteinurias severas se debería a la autolimitación de la infección, al escaso aumento de los inmunocomplejos circulantes y/o a la eliminación renal de los mismos. ${ }^{13}$

La gravedad de estos órganos dañados además del riñón (hígado, miocardio, músculo esquelético, sistema nervioso central y periférico) es muy variable y no existen factores predictores conocidos de severidad. ${ }^{14-20}$ Se cree que infecciones previas con otros serotipos del virus predisponen a una gran liberación de citoquinas que persisten en la memoria inmunológica. Podrían también intervenir comorbilidades como la diabetes mellitus, hipertensión arterial, desnutrición, obesidad, edades extremas de la vida y otros estados de inmunosupresión. ${ }^{21}$

Para el tratamiento del dengue no existen antivirales, sólo se realiza apoyo sintomático sobre todo el manejo adecuado de fluidos en relación a la magnitud de la fuga capilar y la trasfusión de plaquetas cuando la hemorragia es severa. ${ }^{2,22}$

Muchas investigaciones se han propuesto para predecir la severidad del dengue usando parámetros clínicos y laboratoriales. ${ }^{2,3}$ Entre los primeros están los signos de alarma propuestos por la OMS: dolor abdominal, vómitos, hemorragias, letargia o inquietud, hepatomegalia. Entre los parámetros laboratoriales, aparte de la hemoconcentración y la plaquetopenia, se continúa buscando otros criterios diagnósticos rápidos, sencillos, sensibles y específicos que anuncien la severidad de esta infección. ${ }^{11}$ El dengue puede tener una rápida evolución al shock y parece que el seguimiento de estos marcadores laboratoriales es más útil que una determinación aislada. ${ }^{3,23}$

El propósito de este estudio fue investigar el daño de diversos órganos ocurrido durante una epidemia de dengue en el verano del 2012-2013 en el Paraguay, de modo a alertar a los profesionales de la salud sobre la afectación extravascular que muchas veces pasa desapercibida. ${ }^{24}$

\section{Objetivos}

- Describir datos demográficos y procedencia de los pacientes con dengue

- Describir el grado de proteinuria y albuminemia en pacientes con dengue.

- Correlacionar la proteinuria con la fuga capilar medida por el nivel de hemoconcentración de la hemoglobina y hematocrito y con el recuento de plaquetas.

\section{Material y métodos}

Diseño: observacional, descriptivo, prospectivo, de corte transversal.

Población de estudio: varones y mujeres, mayores de edad, portadores de dengue, internados en el Dpto. de Medicina Interna entre diciembre 2012 y mayo 2013.

Criterios de inclusión: Dengue grave con signos de alarma, confirmado por antígeno NS1 y/o IgM positivo, en período crítico o postfebril.

Criterios de exclusión: Portadores de afecciones renales conocidas.

Muestreo: No probabilístico de casos consecutivos.

Variables: Datos demográficos, hemograma, proteinuria de 24 hs, albuminemia. 
Reclutamiento: los sujetos que ingresaban con sospecha de dengue y luego confirmados fueron sometidos a los estudios diagnósticos de afectación renal. El método utilizado para la confirmación de la infección fue la prueba rápida SD BIOLINE Dengue Duo, un ensayo in vitro inmunocromatográfico de un paso diseñado para detectar el antígeno NS1 del virus del dengue en suero, plasma o sangre total humano. El otro método laboratorial confirmatorio fue el SD Dengue IgM Capture ELISA el cual utiliza una enzima inmunoabsorbente para la detección cualitativa de anticuerpos IgM específicos contra el virus del dengue en suero humano. Ambos reactivos son de ESTÁNDAR DIAGNOSTICS, INC, Korea.

Todos los pacientes fueron tratados según el protocolo de tratamiento sugerido en la Guía de Manejo Clínico 2012 del MSP y BS/OPS. ${ }^{2}$

Gestión de datos: las variables fueron registradas en fichas técnicas y trascriptas a planilla electrónica por los autores. Los cálculos estadísticos se realizaron con el programa estadístico Epi Info ${ }^{\odot}$. Las variables nominales se expresaron en porcentajes y las cuantitativas en medias \pm DS. Para el análisis bivariado se utilizó la prueba ANOVA para comparar las variables cuantitativas de distribución normal en varias muestras. La comparación entre variables cuantitativas se realizó con la prueba de correlación de Pearson. Se consideró significativa toda $\mathrm{p}<0,05$.

Aspectos éticos: se respetaron los Principios de la Bioética. Se mantuvo la confidencialidad de los sujetos. No se requirió consentimiento informado por tratarse de un estudio observacional.

\section{Resultados}

Ingresaron al estudio 26 varones con edad media $42 \pm 21$ años y 28 mujeres con edad media $41 \pm 21$ años (p 0,7 prueba ANOVA).

La mayoría de los pacientes procedían de poblaciones próximas al Hospital Nacional, centro de referencia de la región (tabla 1).

\section{TABLA 1}

Procedencia de pacientes con dengue (n 54)

\begin{tabular}{|l|c|c|}
\hline \multicolumn{1}{|c|}{ Procedencia } & Frecuencia & Porcentaje \\
\hline Itauguá & 14 & $25,90 \%$ \\
\hline JA Saldivar & 8 & $14,80 \%$ \\
\hline Capiatá & 7 & $13,00 \%$ \\
\hline Itá & 5 & $9,30 \%$ \\
\hline Ypacaraí & 5 & $9,30 \%$ \\
\hline Guarambaré & 3 & $5,60 \%$ \\
\hline San Pedro & 3 & $5,60 \%$ \\
\hline Asunción & 2 & $3,70 \%$ \\
\hline San Lorenzo & 2 & $3,70 \%$ \\
\hline Otros & 5 & $9,50 \%$ \\
\hline
\end{tabular}


El nivel de proteinuria de 24 hs en toda la muestra tuvo una media de $926 \mathrm{mg} /$ día, DS: $1105 \mathrm{mg} /$ día, rango: $13 \mathrm{mg} /$ día a $5000 \mathrm{mg} /$ día.

La proteinuria se hallaba en rango nefrótico (media $3184 \pm 916 \mathrm{mg} / 24 \mathrm{hs}$ ) en 8 casos $(14,8 \%$ ) y dentro de

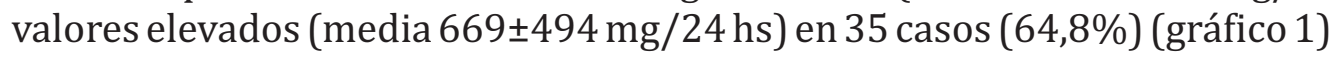

\section{GRÁFICO 1}

\section{Distribución de pacientes con dengue de acuerdo al grado de proteinuria (n 54)}

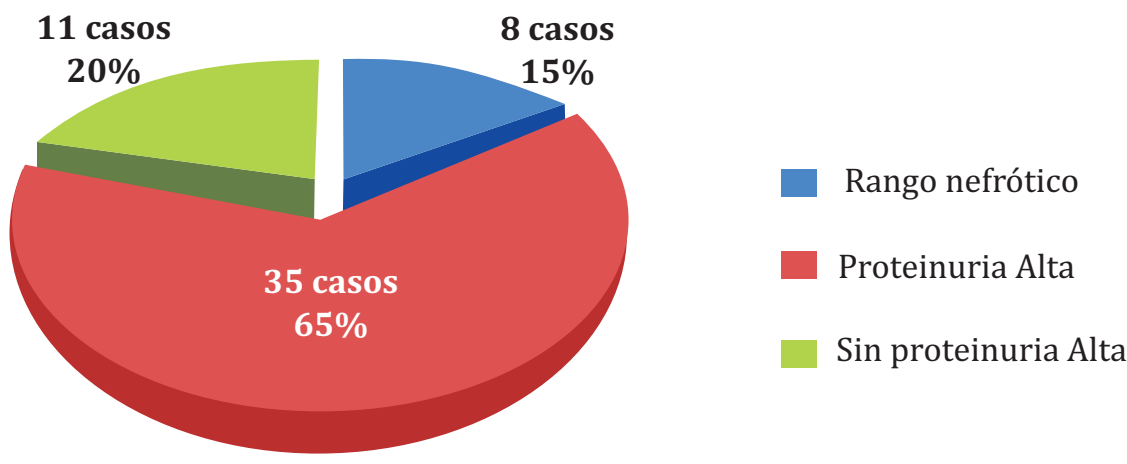

La albuminemia en los sujetos con rango nefrótico fue $3 \pm 0,7 \mathrm{mg} / \mathrm{dL}$, en los que tenían valores elevados de proteinuria fue $2,9 \pm 0,4 \mathrm{mg} / \mathrm{dL}$ y en los sujetos sin proteinuria fue $2,6 \pm 0,4 \mathrm{mg} / \mathrm{dL}$ (p 0,09 prueba ANOVA).

La correlación entre proteinuria y albuminemia fue positiva imperfecta $(r+0,03)$ (gráfico 2).

\section{GRÁFICO 2}

\section{Correlación entre proteinuria y albuminemia (n 54)}

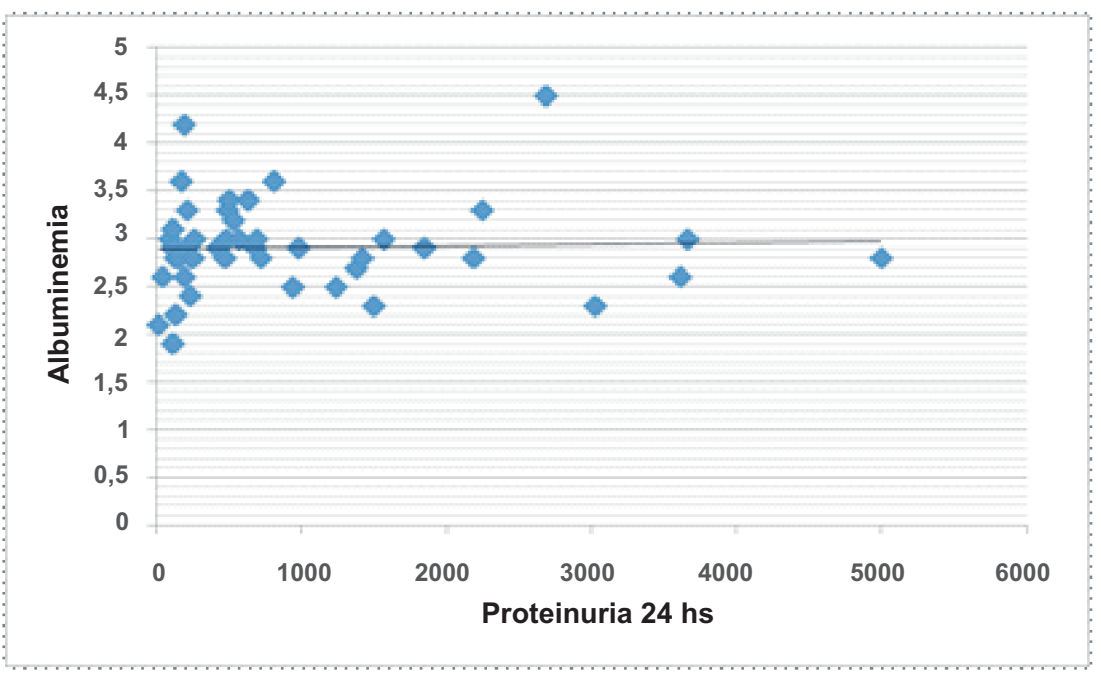

Se calculó el grado de hemoconcentración tomando los valores más altos (al ingreso del paciente) y los valores más bajos (al egreso del paciente) de la hemoglobina ( $\mathrm{Hb}$ ) y del hematocrito (Hcto). Se consideró que el paciente estuvo con severa hemoconcentración si el valor era $\geq 20 \%{ }^{2}$ 
Correlacionando el grado de hemoconcentración de la $\mathrm{Hb}$ con el nivel de proteinuria, se obtuvo una correlación negativa imperfecta (r -0,01) (gráfico 3).

\section{GRÁFICO 3}

\section{Correlación entre proteinuria y grado de hemoconcentración de hemoglobina (n 54)}

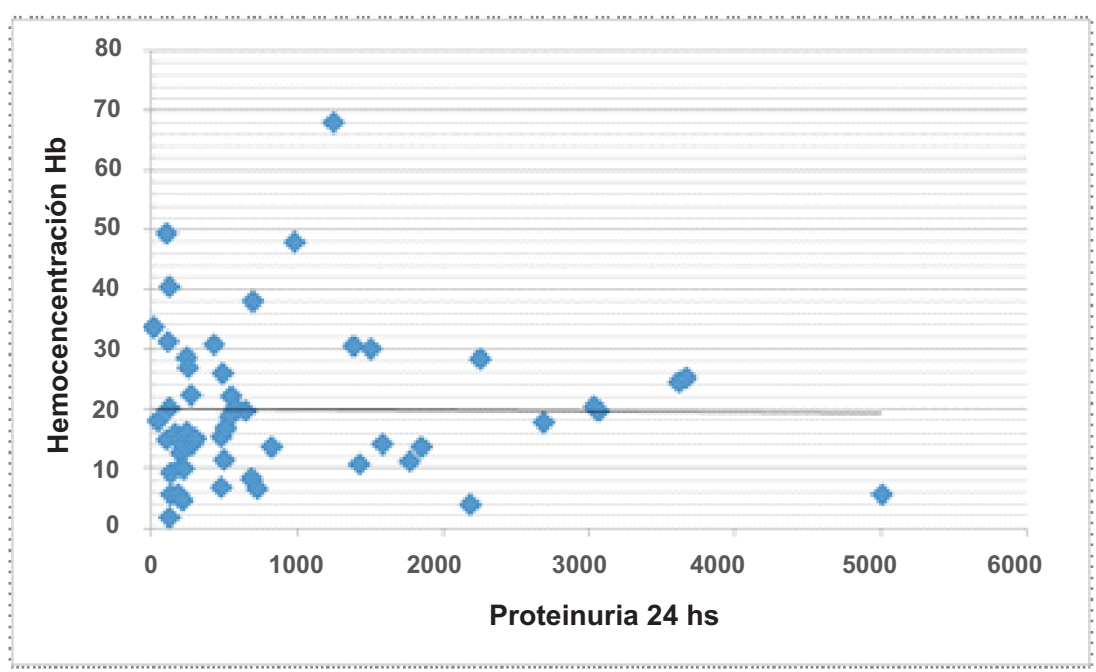

La correlación entre grado de hemoconcentración del Hcto con el nivel de proteinuria mostró una correlación negativa imperfecta (r-0,04) (gráfico 4).

\section{GRÁFICO 4}

\section{Correlación entre proteinuria y el grado de hemoconcentración del hematocrito (n 54)}

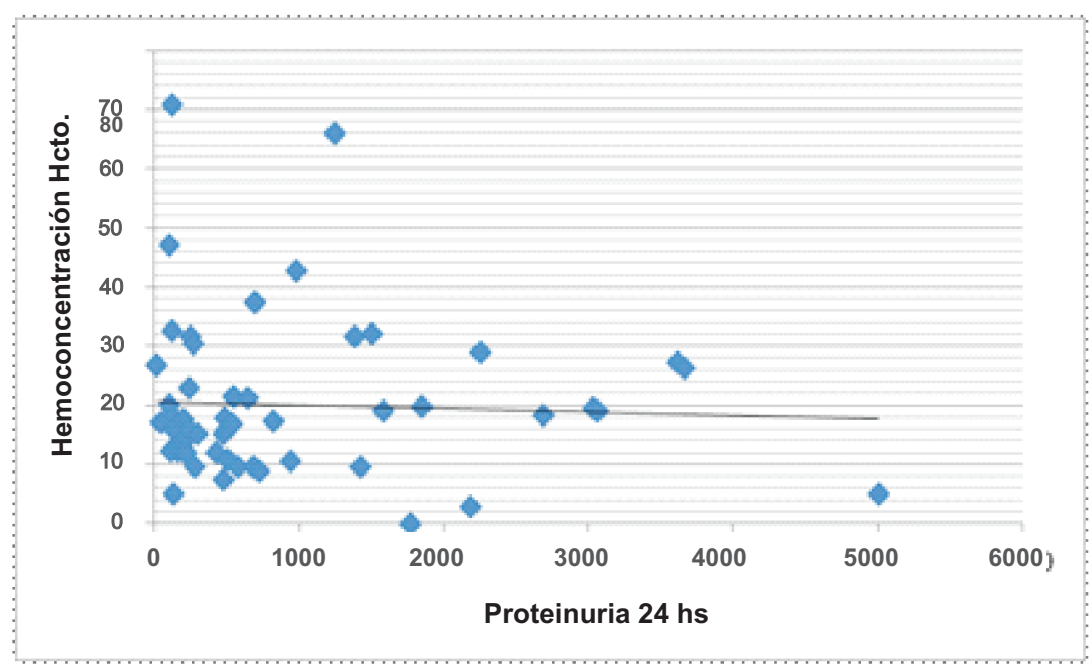

Otro marcador de gravedad del dengue es la plaquetopenia. Se realizó un correlación entre la proteinuria y el recuento más bajo de plaquetas, obteniéndose una correlación negativa imperfecta $(\mathrm{r}-0,1)$ (gráfico 5). 


\section{GRÁFICO 5}

\section{Correlación entre proteinuria y plaquetopenia (n 54)}

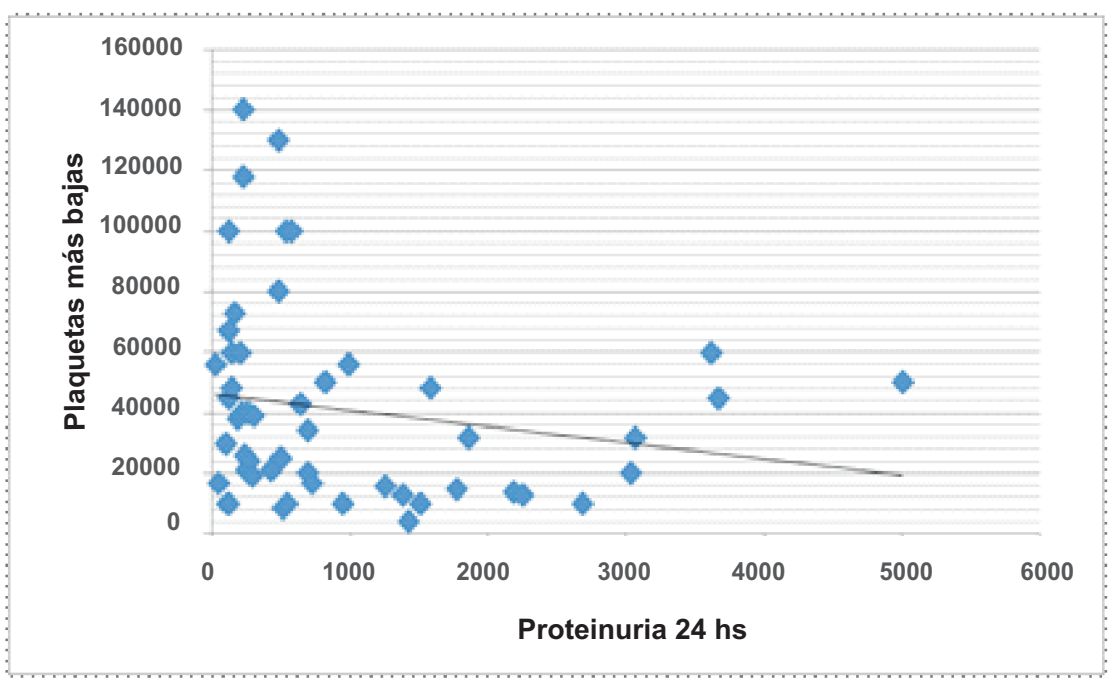

\section{Discusión}

El ligero predominio de mujeres en esta muestra es un fenómeno común observado en el país y en la región. ${ }^{25}$ Posiblemente esto se deba a los hábitos domiciliarios del vector.

Los niveles de proteinuria anormalmente elevados alcanzaron una proporción de 80\%, hallazgo sumamente llamativo, ya que ningún paciente presentó afectación funcional renal grave ni persistente. Tampoco puede atribuirse este hallazgo a la coexistencia de nefropatías previas, ya que estos sujetos fueron excluidos del estudio.

La proteinuria ya fue observada por otros autores en muchos casos de dengue, aún sin evidencia de afectación funcional renal. La presencia y severidad de la proteinuria ha sido postulada como factor de riesgo potencial de un dengue severo, aunque hay poca información de la magnitud, tiempo de inicio y evolución de este fenómeno durante la infección. ${ }^{3}$

En esta serie, todos los pacientes eran portadores de dengue grave con signos de alarma, aunque ninguno estaba en shock o con otra condición que amerite ingreso a sala de terapia intensiva. Los pacientes ambulatorios, con dengue y sin signos de alarma, no ingresaron a este estudio. Sería interesante evaluar los niveles de proteinuria en esas situaciones.

La ausencia de correlación significativa de la proteinuria con los signos de fuga capilar (estados de hemoconcentración de la hemoglobina y del hematocrito) y con el recuento de plaquetas posiblemente se deba al tamaño de la muestra, aunque se sabe que cada paciente responde de manera diferente a esta infección. Desafortunadamente no disponemos de datos de que nuestros pacientes hayan padecido dengue anteriormente. Se sabe que las infecciones sucesivas con diferentes serotipos produce una gran liberación de citoquinas, con marcada afectación sistémica. Tal vez este mecanismo explique estas correlaciones halladas. ${ }^{26,27}$

Muchos investigadores esperan incorporar un test de detección sensible y específico de proteínas en orina en todo paciente con sospecha de dengue. ${ }^{11,12}$ Es más, sería recomendable la medición del complemento y biopsia renal en casos de síndrome nefrótico, para demostrar glomerulonefritis asociadas al dengue. 13,28,29 
Concluyendo, el dengue produjo proteinuria en 79,6\% de los pacientes, llegando a rango nefrótico en 14,8\%. La proteinuria no se asoció con el grado de hemoconcentración de la hemoglobina ni del hematocrito, parámetros utilizados como indicadores de gravedad de la fuga capilar. La proteinuria tampoco se asoció al recuento de plaquetas.

Se recomienda agregar el dosaje de proteínas en orina de 24 hs al protocolo de tratamiento del dengue y el seguimiento prospectivo de los afectados con rango nefrótico. Es necesario descifrar la fisiopatología de la afectación renal, con ayuda de biopsias e inmunofluorescencia, así como con autopsias, si procede.

\section{Nota}

Este estudio obtuvo una Mención de Honor entre los temas libres orales en el VIII Congreso de la Sociedad Latinoamericana de Medicina Interna SOLAMI (Luque, Paraguay, agosto 2013)

\section{Referencias bibliográficas}

1. $\quad$ Simmons CP, Farrar JJ, Nguyen vV, Wills B. Dengue. N Engl J Med. 2012 Apr 12; 366(15): 1423-32

2. MSP y BS. Dengue. Guía de Manejo Clínico 2012. Disponible en http://www.mspbs.gov.py. Visitado 9 febrero 2013

3. Hanh Tien NT, Lam PK, Duyen HT, Ngoc TV, Ha PT, Kieu NT, Simmons C, Wolbers M, Wills B. Assessment of microalbuminuria for early diagnosis and risk prediction in dengue infections. PLoS One. 2013;8(1):e54538.

4. Wang SM, Sekaran SD. Evaluation of a commercial SD dengue virus NS1 antigen capture enzyme-linked immunosorbent assay kit for early diagnosis of dengue virus infection. J Clin Microbiol. 2010 Aug;48(8):2793-71.

5. Bisordi I, Rocco IM, Suzuki A, Katz G, Silveira VR, Maeda AY et al. Evaluation of dengue NS1 antigen detection for diagnosis in public health laboratories, São Paulo State, 2009. Rev Inst Med Trop Sao Paulo. 2011 NovDec;53(6):315-20.

6. Pan-Ngum W, Blacksell SD, Lubell Y, Pukrittayakamee S, Bailey MS, de Silva HJ et al. Estimating the true accuracy of diagnostic tests for dengue infection using bayesian latent class models. PLoS One. 2013;8(1):e50765.

7. Fry SR, Meyer M, Semple MG, Simmons CP, Sekaran SD, Huang JX, McElnea C et al. The diagnostic sensitivity of dengue rapid test assays is significantly enhanced by using a combined antigen and antibody testing approach. PLoS Negl Trop Dis. 2011 Jun;5(6):e1199.

8. Gowri Sankar S, Dhananjeyan KJ, Paramasivan R, Thenmozhi V, Tyagi BK, John Vennison S. Evaluation and use of NS1 IgM antibody detection for acute dengue virus diagnosis: report from an outbreak investigation. Clin Microbiol Infect. 2012 Jan;18(1):E8-10.

9. Basu A, Chaturvedi UC. Vascular endothelium: the battlefield of dengue viruses. FEMS Immunol Med Microbiol. 2008 Aug;53(3):287-99.

10. Lin CF, Wan SW, Cheng HJ, Lei HY, Lin YS. Autoimmune pathogenesis in dengue virus infection. Viral Immunol. 2006 Summer;19(2):127-32.

11. Vasanwala FF, Puvanendran R, Fook-Chong S, Ng JM, Suhail SM, Lee KH. Could peak proteinuria determine whether patient with dengue fever develop dengue hemorrhagic/dengue shock syndrome?--a prospective cohort study. BMC Infect Dis. 2011 Aug 5;11:212.

12. Wills BA, Oragui EE, Dung NM, Loan HT, Chau NV, Farrar JJ, Levin M. Size and charge characteristics of the protein leak in dengue shock syndrome. J Infect Dis. 2004 Aug 15;190(4):810-8.

13. Vasanwala FF, Puvanendran R, Ng JM, Suhail SM. Two cases of self-limiting nephropathies secondary to dengue haemorrhagic fever. Singapore Med J. 2009 Jul;50(7):e253-5.

14. Acharya S, Shukla S, Mahajan SN, Diwan SK. Acute dengue myositis with rhabdomyolysis and acute renal failure. Ann Indian Acad Neurol. 2010 Jul;13(3):221-2.

15. Sung JM, Lee CK, Wu-Hsieh BA. Intrahepatic infiltrating NK and CD8 T cells cause liver cell death in different phases of dengue virus infection. PLoS One. 2012;7(9):e46292. 
16. Kaushik JS, Gupta P, Rajpal S, Bhatt S. Spontaneous resolution of sinoatrial exit block and atrioventricular dissociation in a child with dengue fever. Singapore Med J. 2010 Sep;51(9):e146-8.

17. Verma R, Sharma P, Garg RK, Atam V, Singh MK, Mehrotra HS. Neurological complications of dengue fever: Experience from a tertiary center of north India. Ann Indian Acad Neurol. 2011 Oct;14(4):272-8.

18. Sangle SA, Dasgupta A, Ratnalikar SD, Kulkarni RV. Dengue myositis and myocarditis. Neurol India. 2010 JulAug;58(4):598-9.

19. Lim M, Goh HK. Rhabdomyolysis following dengue virus infection. Singapore Med J 2005;46:645-6.

20. Muzaffar J, Venkata Krishnan P, Gupta N, Kar P. Dengue encephalitis: why we need to identify this entity in a dengueprone region. Singapore Med J. 2006 Nov;47(11):975-7.

21. Malavige GN, Huang LC, Salimi M, Gomes L, Jayaratne SD, Ogg GS. Cellular and cytokine correlates of severe dengue infection. PLoS One. 2012;7(11):e50387.

22. Simmons CP, Wolbers M, Nguyen MN, Whitehorn J, Shi PY, Young P, Petric R, Nguyen VV, Farrar J, Wills B. Therapeutics for dengue: recommendations for design and conduct of early-phase clinical trials. PLoS Negl Trop Dis. 2012;6(9):e1752.

23. Halstead SB. Dengue: the syndromic basis to pathogenesis research. Inutility of the 2009 WHO case definition. Am J Trop Med Hyg. 2013 Feb;88(2):212-5.

24. Thein TL, Gan VC, Lye DC, Yung CF, Leo YS. Utilities and limitations of the World Health Organization 2009 warning signs for adult dengue severity. PLoS Negl Trop Dis. 2013;7(1):e2023.

25. Souza LJ, Boulos M. Clinical experience in dengue: experience of specialized service. Rev Inst Med Trop Sao Paulo. 2012 Oct;54 Suppl 18:S7-9.

26. Malavige GN, Huang LC, Salimi M, Gomes L, Jayaratne SD, Ogg GS. Cellular and cytokine correlates of severe dengue infection. PLoS One. 2012;7(11):e50387.

27. Patkar C, Giaya K, Libraty DH. Dengue virus type 2 modulates endothelial barrier function through CD73. Am J Trop Med Hyg. 2013 Jan;88(1):89-94

28. Hutspardol S, Prommalikit O, Upiya N, Chataroopwijit J, Khemakanok K, Assadamongkol K. Heavy proteinuria following dengue hemorrhagic fever. Southeast Asian J Trop Med Public Health. 2011 May;42(3):579-82.

29. Lumpaopong A, Kaewplang P, Watanaveeradej V, Thirakhupt P, Chamnanvanakij S, Srisuwan K, Pongwilairat N, Chulamokha Y. Electrolyte disturbances and abnormal urine analysis in children with dengue infection. Southeast Asian J Trop Med Public Health. 2010 Jan;41(1):72-6. 